\title{
Are there any solutions for improving the cleft area hygiene in patients with cleft lip and palate? A systematic review
}

\author{
Rita Rodrigues $^{1,2}$ (D) | Maria Helena Fernandes ${ }^{1,3}$ (i) | António Bessa Monteiro ${ }^{4}$ | \\ Rowney Furfuro $^{5}$ | Cátia Carvalho Silva ${ }^{2}$ (D) | Ricardo Vardasca ${ }^{6}$ (D) | \\ Joaquim Mendes $^{6}$ (D) | Maria Conceição Manso ${ }^{3,7}$ (D)
}

${ }^{1}$ Faculty of Dentistry, U. Porto, Porto,

Portugal

${ }^{2}$ Faculty of Health Sciences, University Fernando Pessoa, Porto, Portugal

${ }^{3}$ Associated Laboratory for Green Chemistry (LAQV/REQUIMTE), Porto, Portugal

${ }^{4}$ Lusiadas Hospital, Porto, Portugal

${ }^{5}$ Compor Clinic, Porto, Portugal

${ }^{6}$ Faculty of Engineering, U. Porto, Porto, Portugal

${ }^{7}$ Faculty of Health Sciences, University Fernando Pessoa, Fernando Pessoa Energy, Environment and Health Research Unit (FPENAS), Porto, Portugal

\section{Correspondence}

Maria Conceição Manso, Faculty of Health

Sciences, University Fernando Pessoa,

Porto, Portugal.

Email cmanso@ufp.edu.pt

\section{Funding information}

Fundação para a Ciência e a

Tecnologia, Grant/Award Number:

UID/Multi/04546/2016 and UID/

QUI/50006/2013-POCI/01/0145/

FERDER/007265

\begin{abstract}
Objective: Children with cleft lip and palate (CLP) present high incidence of oral health problems, namely those associated with the accumulation of dental plaque. The objective of this systematic review was to verify if there is any solution to improve the hygiene of the cleft area.

Materials and methods: A structured systematic review was performed based on articles published in several electronic databases: PubMed, Web of Science, Cochrane Library and Scopus in the last 20 years. The MeSH terms used were cleft lip, palate, harelip, oral hygiene and toothbrush.

Results: From 270 potentially relevant articles, 39 articles were selected, corresponding to a total of 3226 CLP patients and 914 matched controls. The selected studies exhibited great heterogeneity regarding the type of the study, study population (average range 0 -49 years old; sampling sizes 15-400 CLP patients), evaluation periods, reported variables and oral hygiene routines. Consensual outcomes were the presence of high plaque indexes, high prevalence of dental caries and worse oral hygiene patterns in CLP patients. Additionally, poor education in oral health and low motivation to integrate regular hygiene routines in the daily family life were also evident.

Conclusion: There is a clear need to improve the oral hygiene care of CLP children, but few studies were focused on specific preventive approaches. Development of devices especially designed to the hygiene of the cleft area and implementation of standardized prevention and control programmes targeting education, motivation and compliance would contribute to improve oral health in CLP children.
\end{abstract}

KEYWORDS

cleft lip palate, dental caries, dental hygiene, DMF-S/T, harelip, oral hygiene, toothbrush

\section{1 | INTRODUCTION}

Cleft lip and palate (CLP) are the most common congenital malformations of the face. Clinically, the anatomic-functional alteration of one or many structures (lip, alveolar process, hard and soft palate) is observed. The cleft lip (CL), or cleft palate (CP), can occur alone or together, and might be complete or incomplete, uni or bilateral.

The anatomical and morphological development disturbances in children with CLP are associated with high incidence of oral health problems, namely those related to the accumulation of dental 

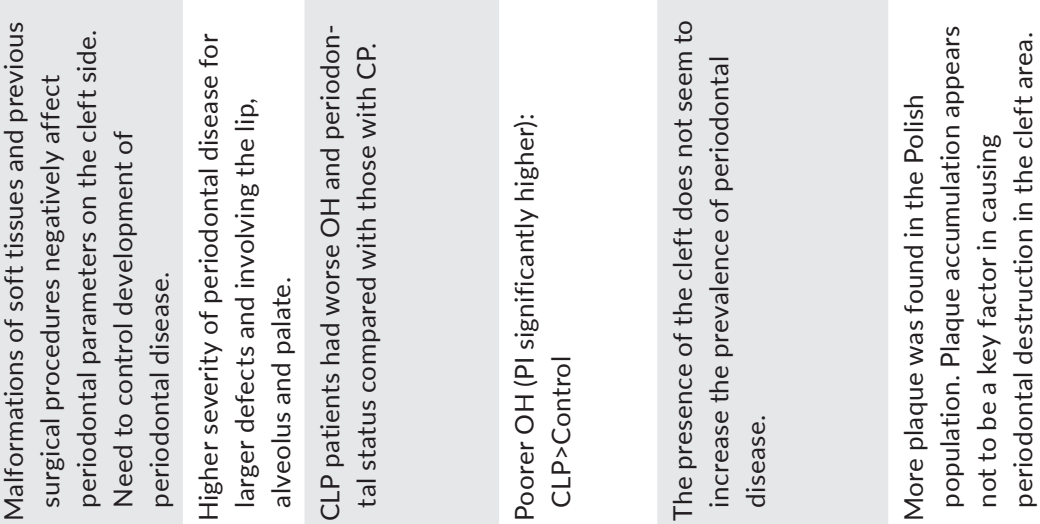

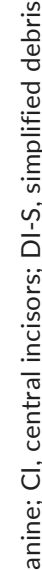
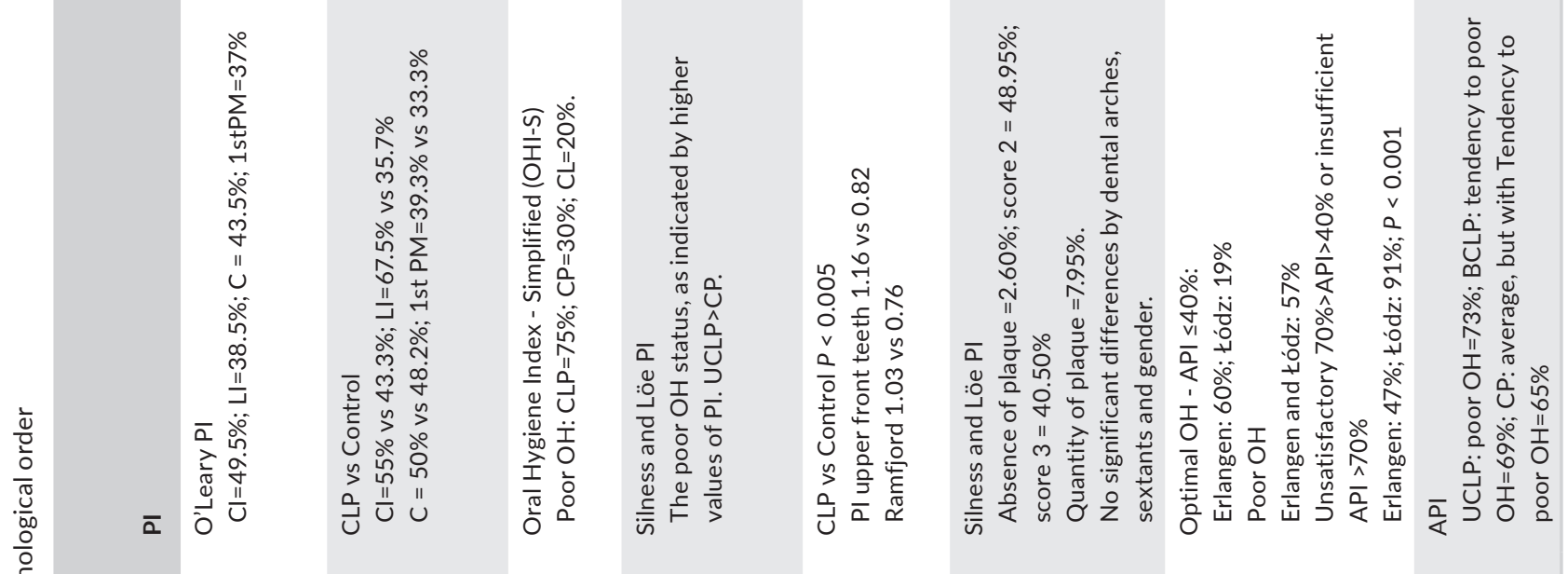

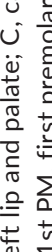
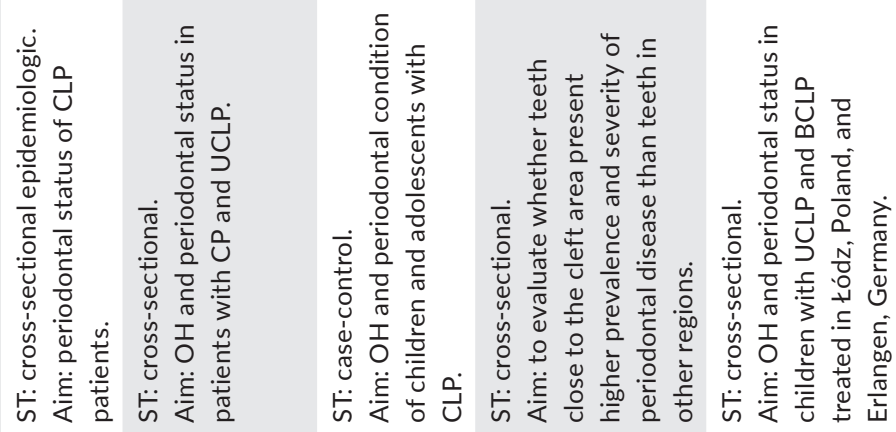

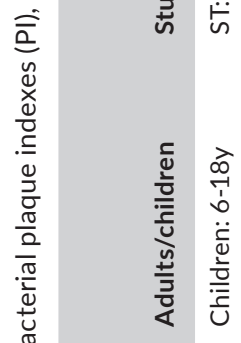

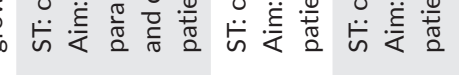

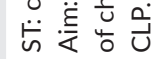
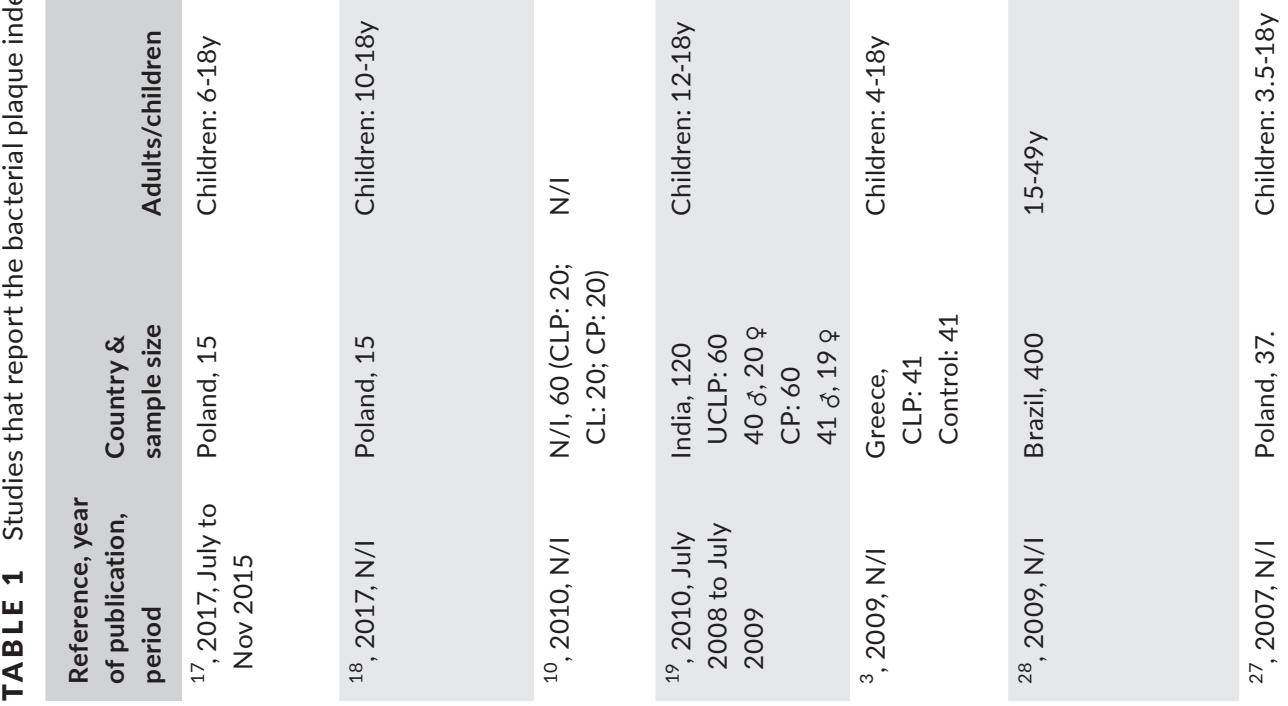

uิ

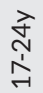

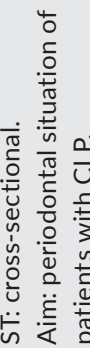

$\frac{\mathrm{U}}{\mathrm{T}} \frac{\mathrm{d}}{\frac{\pi}{0}}$

䨌

를 $\frac{\pi}{\overline{0}}$

U. 은 중 党 $\frac{\pi}{\frac{1}{2}}$

$\frac{2}{\circ} \frac{0}{0}$ 
plaque. ${ }^{1-3}$ As a result, there is a high prevalence of dental caries in these children. ${ }^{4,5}$

A number of reasons account to the difficulty in performing a proper oral hygiene, including in the cleft area, among them, fear of soft tissue trauma during brushing, concern about bleeding from inflamed gingiva, difficult to assess the teeth and the deepest area of the cleft and the decreased flexibility of surgical repaired lip. ${ }^{6,7}$ Appropriate hygiene is also needed for the abnormally positioned supernumerary tooth or teeth that may appear in the cleft area. This anatomical feature is an additional factor that hampers the maintenance of good local hygiene. ${ }^{8}$

The relevance of oral hygiene to improve oral health is highlighted in a variety of studies. ${ }^{2,6,8-10}$ It is also required for the successful outcome of the surgical corrective procedures. Dietary counselling and the use of antiseptic mouthwash help to minimize the problem but nothing compares with the efficacy of toothbrushing to remove dental plaque. $8,9,11,12$

In spite of that, epidemiological studies on the oral hygiene of CLP children are scarce, and do not address the hygiene of the cleft area. The available information is quite dispersed and heterogeneous. Reported studies have notorious differences in the protocols, that is concerning the study population, evaluation period, measured variables and hygiene routines.

The aim of this systematic review is to critically select and analyse the literature information to verify if there is any solution to improve the hygiene of the cleft area. It is believed that this would fill a gap by providing comprehensive and easily accessible knowledge to the health professionals enrolled in treatment and preventive oral health programs targeting this population.

\section{2 | MATERIALS AND METHODS}

\section{1 | Focused question}

Are there any solutions for improving the cleft area hygiene in patients with clefts? Therefore, the main outcome of this systematic review is "instruments to improve the hygiene of the cleft area."

\section{2 | Search strategy}

A structured literature search was performed on the reference bibliographic databases: PubMed, Web of Science, Cochrane Library and Scopus, from January 1997 to November 2017.

The MeSH terms used were Cleft lip, palate, harelip, oral hygiene and toothbrush, and the "AND" and "OR" Boolean operators were applied to combine keywords, respectively: ((CLEFT LIP AND PALATE) OR HARELIP) AND (ORAL HYGIENE); ((CLEFT LIP AND PALATE) OR HARELIP) AND TOOTHBRUSH. The choice of keywords was meant to be simple and since "cleft lip and palate" and "harelip" are synonyms, and most of the times are used as an alternative for one another, they were also included in the research in order to identify older studies which used this term, using the OR Boolean operator, adjunct with the main word of "cleft lip and palate.".

\section{3 | Screening and selection}

At first, title and abstract screening was performed. The inclusion criterion was the selection of articles in which oral hygiene in CLP patients was performed with a clinical purpose. The following exclusion criteria were applied:

- Meta-analysis and systematic reviews which are already a collection of previous studies included case reports, case series, descriptive studies, opinion articles, letters, responses to letters and articles that did not analyse oral hygiene in CLP patients;

- Studies related to patients using fixed appliances;

- Cases of bone graft;

- Single cases and syndromes;

- Articles focused on morphological teeth anomalies and nutritional health;

- Articles written in a language other than English;

The guidelines of Transparent Reporting of Systematic Reviews and Meta-analyses (PRISMA) ${ }^{13}$ were followed throughout the process.

Data from the selected articles were independently extracted by two researchers (RR, MCM) using a standardized form. Standard risk of bias tools was not applicable for this study type. Disagreements were resolved through discussion with a third reviewer (CCS). The extracted information was organized in three tables: characterization of bacterial plaque assessed by any quantitative index (Table 1), prevalence of dental caries assessed by $\mathrm{dmft} / \mathrm{dmfs}$ and/or DMFT/DMFS (Table 2) and both issues (Table 3). Information collected on the oral hygiene routines (brushing habits, use of fluoride supplementation) is not present in the tables, but it is also described and discussed.

\section{3 | RESULTS}

\subsection{Search and selection}

The literature search identified a total of 270 potentially relevant papers. Excluded studies included: duplicate studies $(n=119)$, studies not fulfilling the aim of this review (95), not fully accessible articles (10) and articles not written in English (6).

At the end, 39 articles were selected to be included in this systematic review. PRISMA flow diagram describing the methodology is presented in Figure 1.

\subsection{Heterogeneity}

The studies included in this review exhibited extensive heterogeneity concerning the type, geographic area, age range, evaluation period and evaluated oral health parameters.

Regarding the study type, the review analysed 21 cross-sectionals $^{1,14,15} ; 9$ case-controls ${ }^{2,3,5,6,8,12,34,35} ; 2$ epidemiological ${ }^{4,7} ; 1$ retrospective quantitative descriptive ${ }^{37} ; 1$ observational, cross-sectional $^{38} ; 1$ prospective ${ }^{39} ; 1$ qualitative research ${ }^{11}$ and 2 narrative reviews. 9,40 

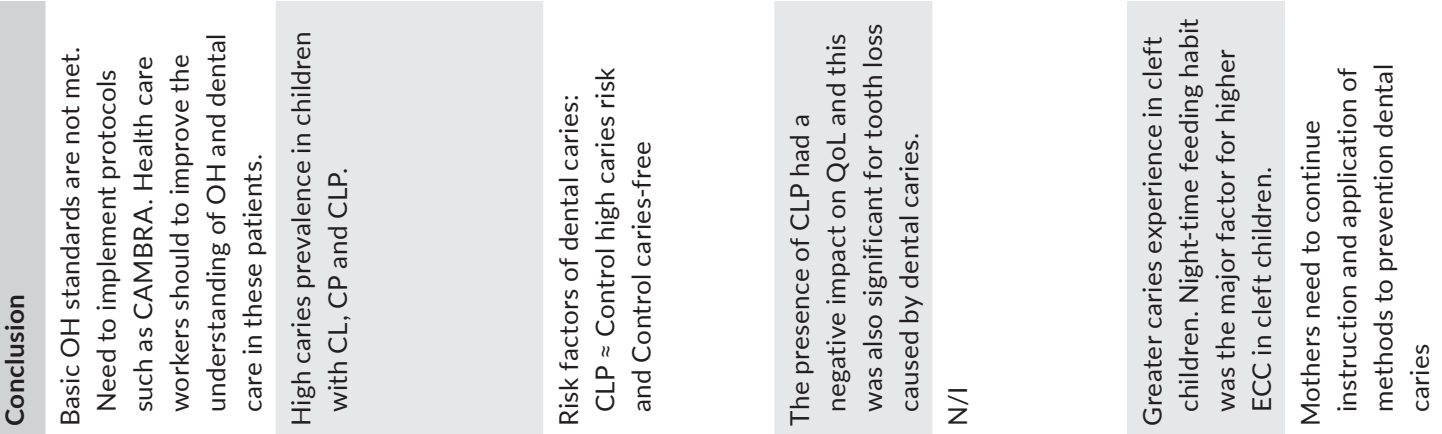

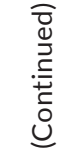
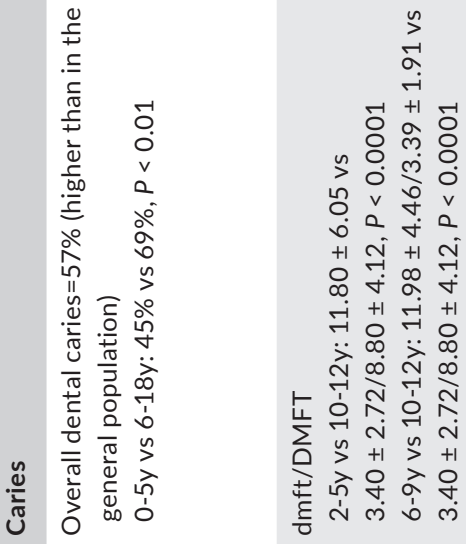

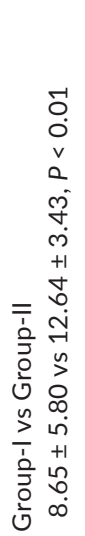
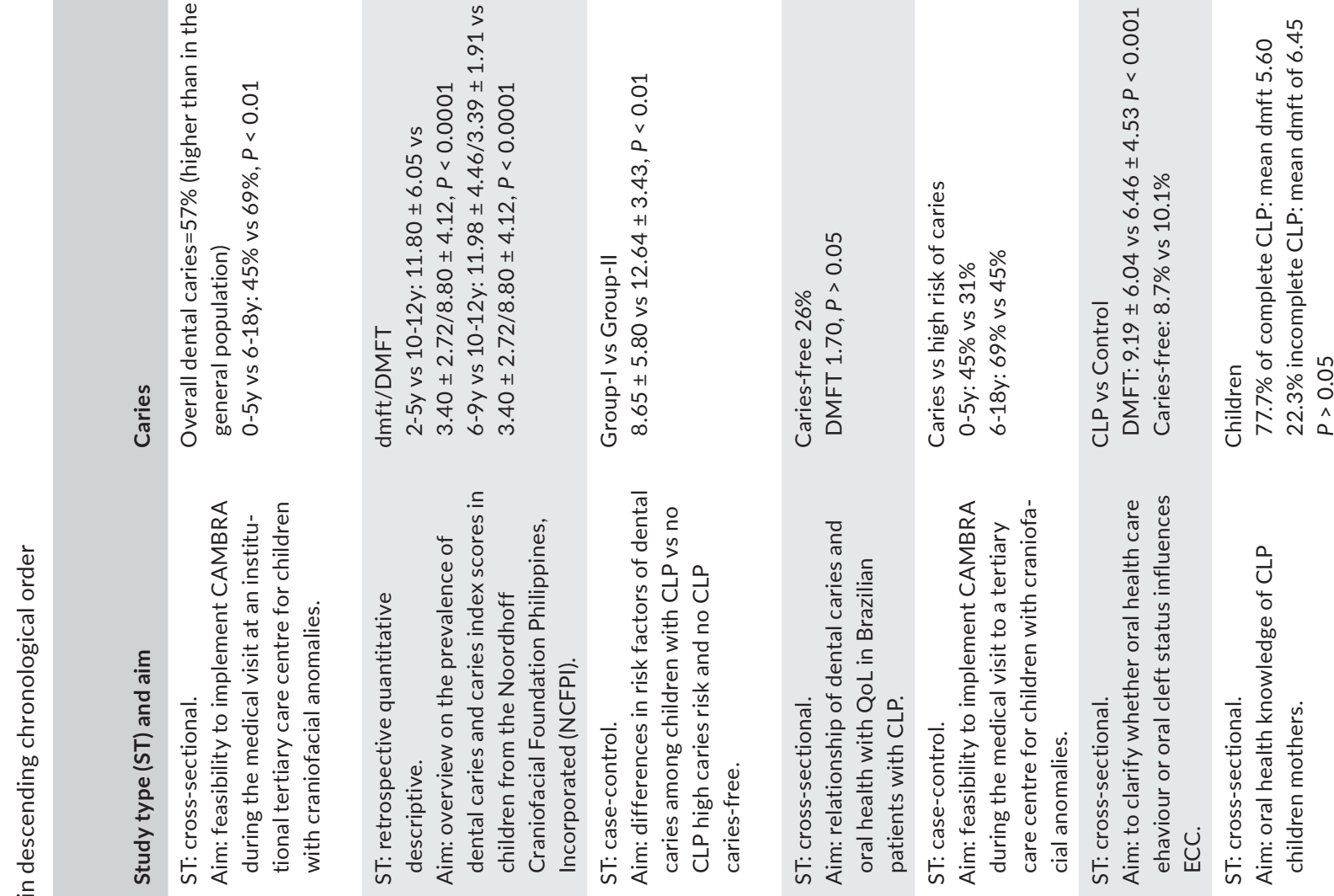

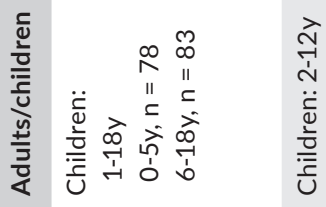

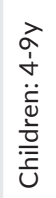
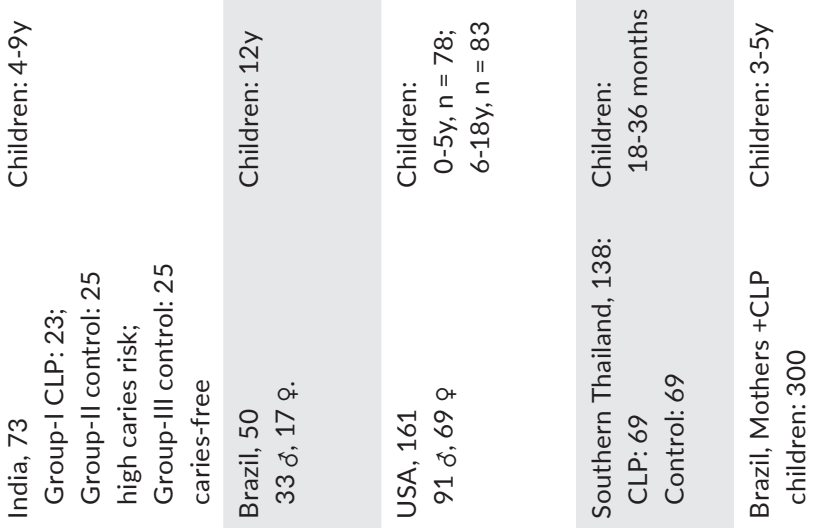

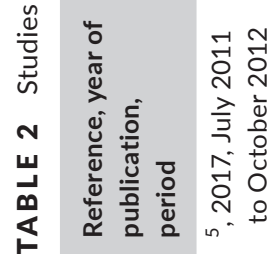

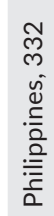

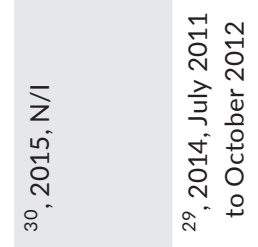

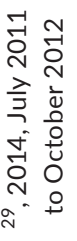

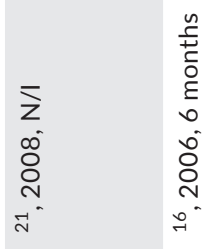




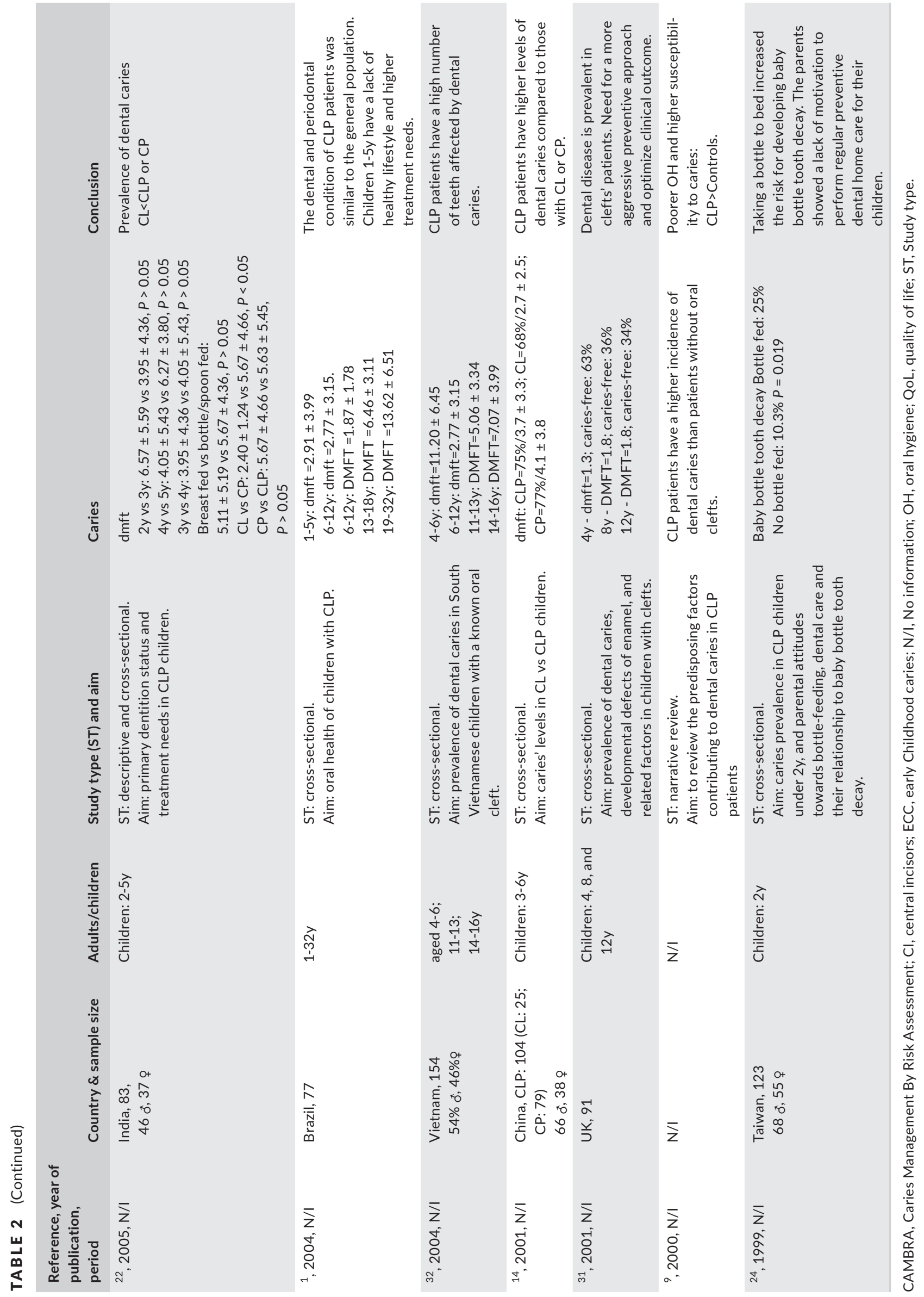



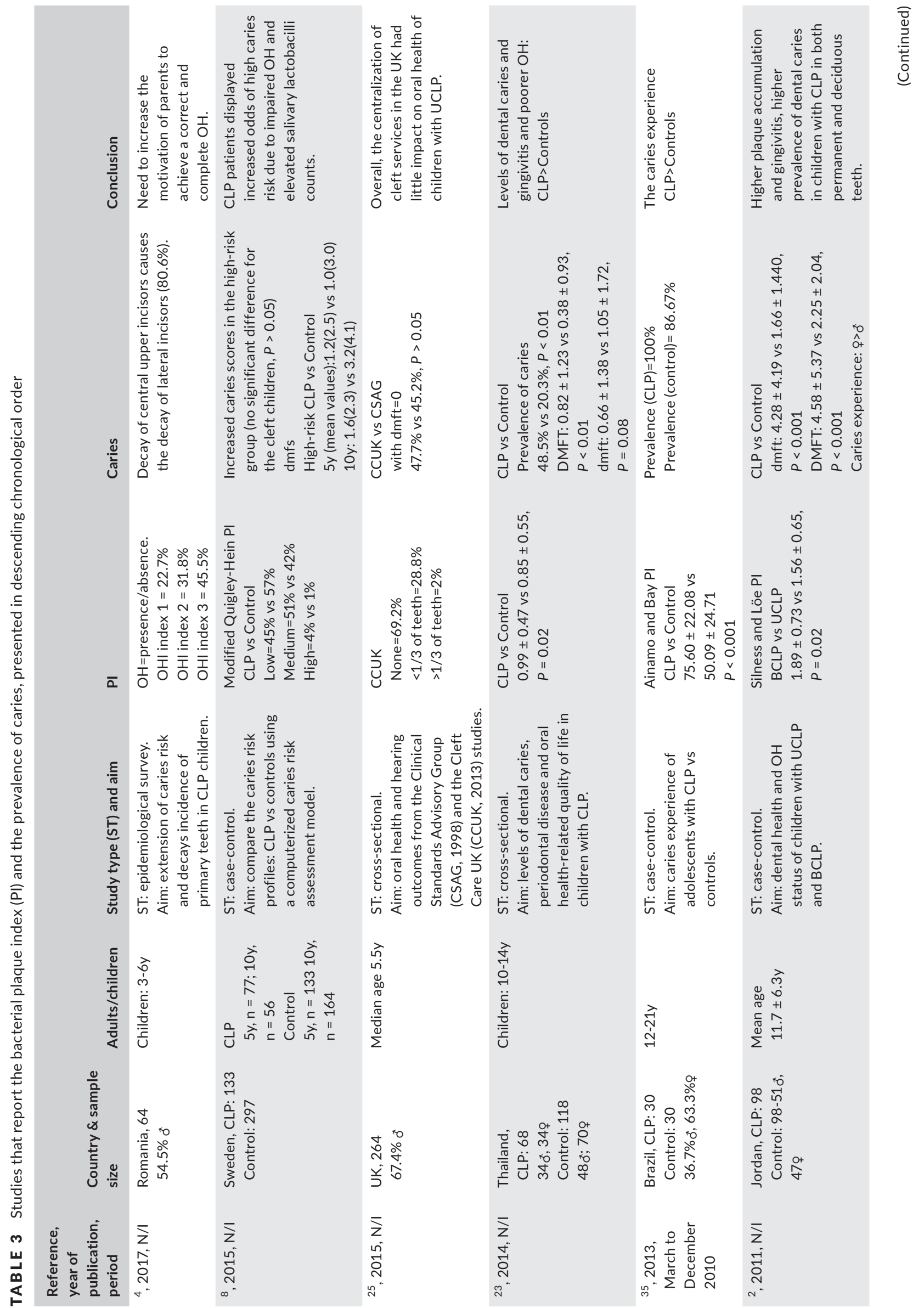

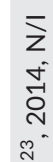

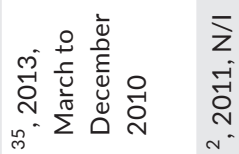




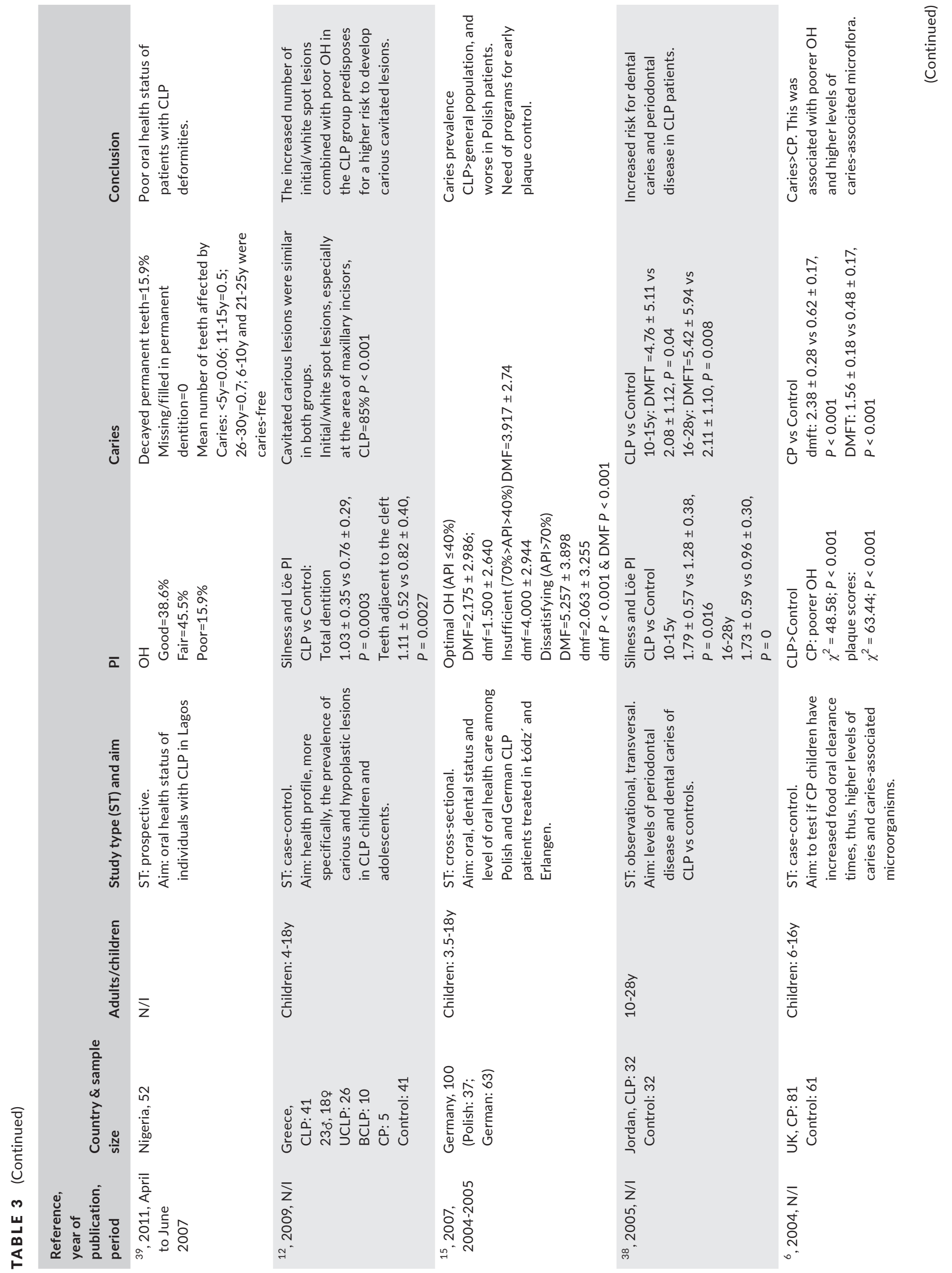




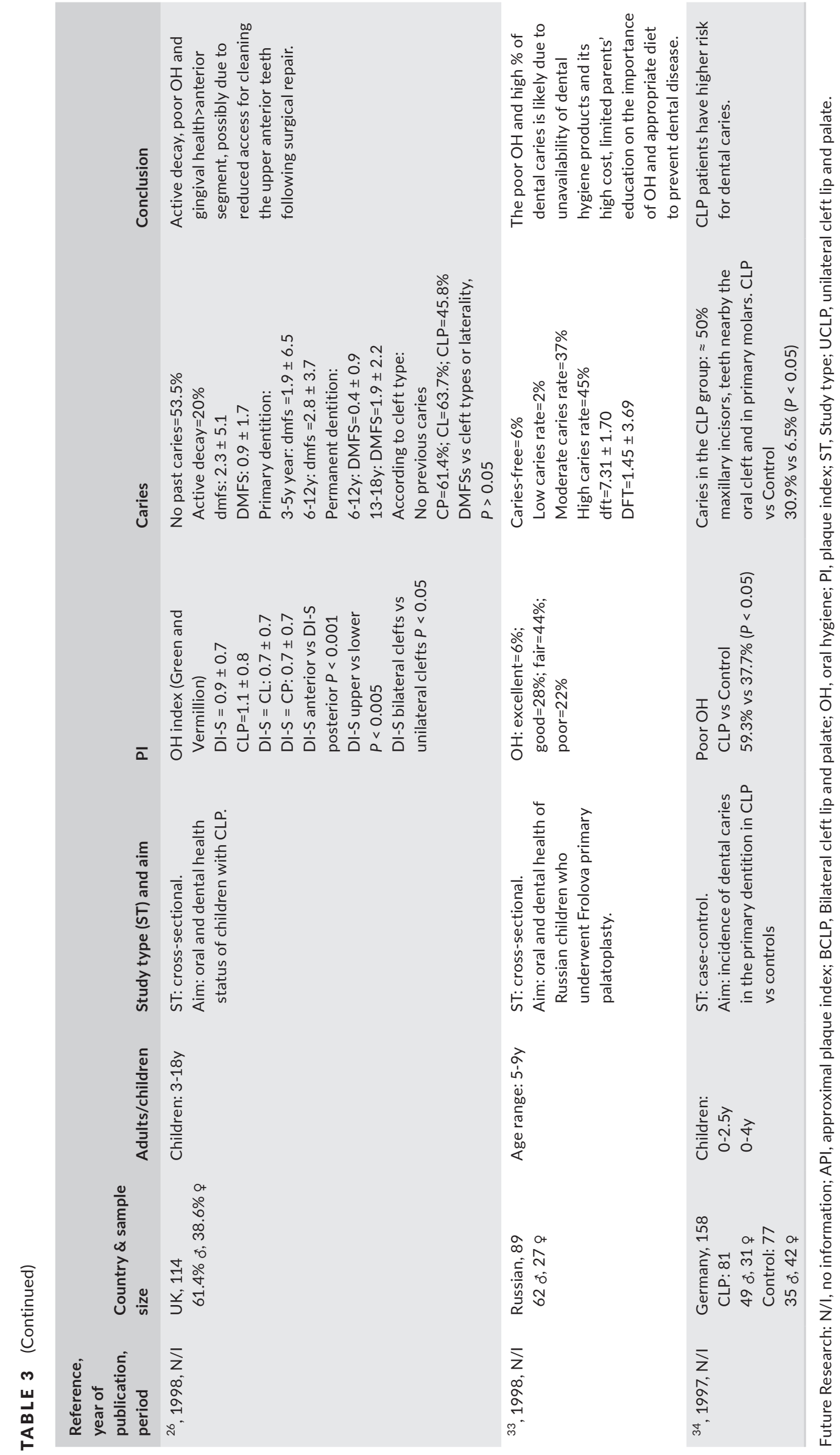




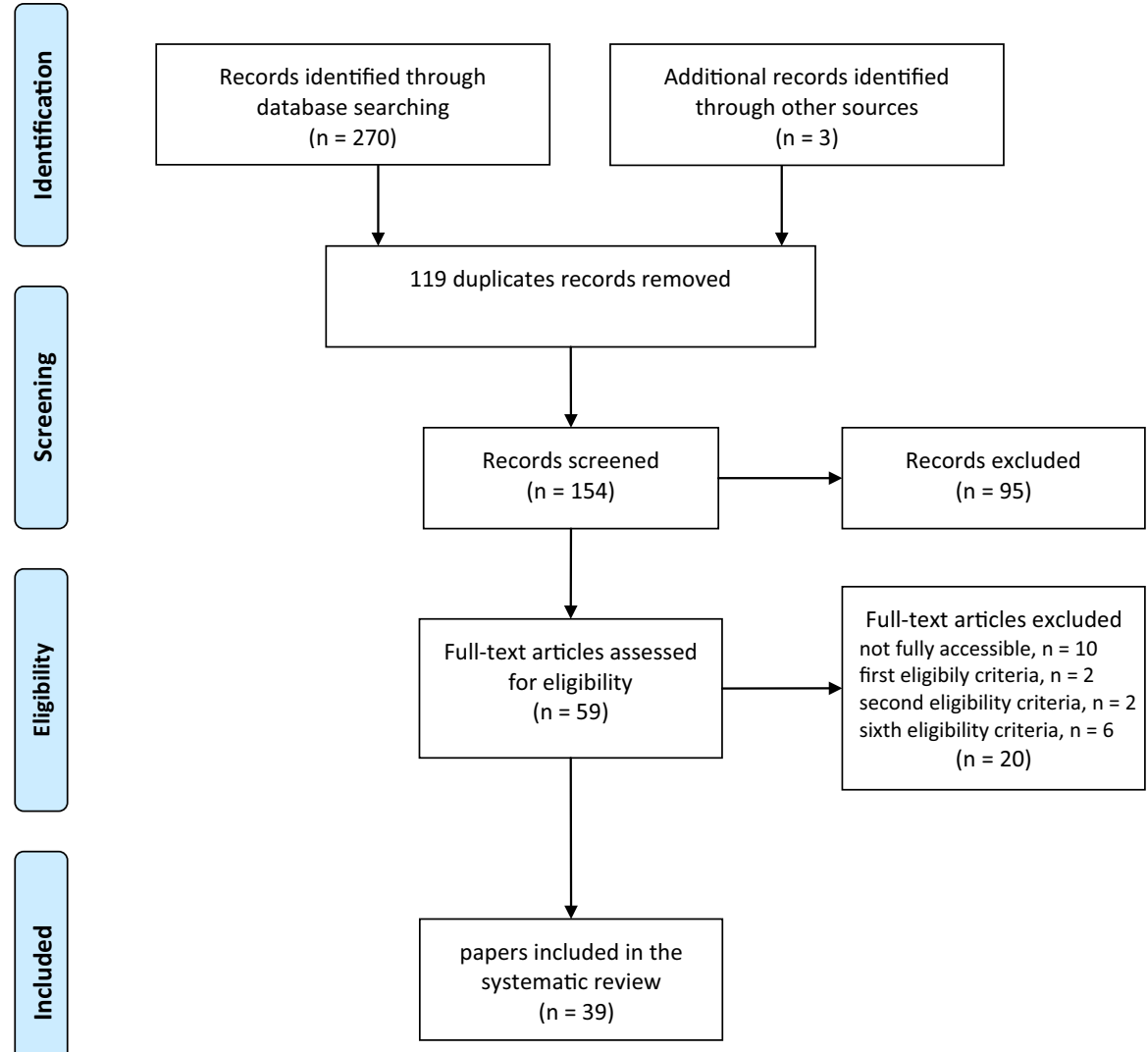

FIGURE 1 Information flow with the different phases of the search and selection process
Fifteen studies were conducted in European populations, ${ }^{3,4,6,8,11,12,15,17,18,20,25-27,31}$ thirteen from Asia, 2,7,14,19,21-24,32,33 five from South America, ${ }^{1,16,28,30,35}$ two from North America, ${ }^{5,29}$ one from Africa ${ }^{39}$ and three studies do not mention the country. $9,10,40$

The age range varied from 0 to 49 years old, and the studies ad-

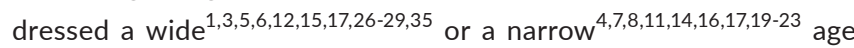
range, and some of them refereed only the mean age. .,25 $^{2,}$

Most of the studies do not report on the evaluation period. $^{1-4,6-12,14,17}$ About the oral health indexes, the plaque index was not reported in a variety of studies. ${ }^{1,5,7,9,11,14,21,22,24,29-32,36}$ Also, some of them address caries lesions other than those related to bacterial plaque $\mathrm{e}^{1,3,5,10,14,16,17,19-22,24,27-29}$ and others investigate both issues. . $4,6,8,12,15,23,25,26,33-35,38$ Information on brushing frequency and/or

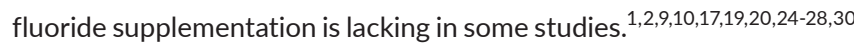

\section{3 | Outcomes}

The 39 studies included in this review involved a total of 3226 CLP patients and 914 matched control patients, sampling sizes of 15-400 CLP patients and were published between 1997 and 2017. It was possible to perceive that the main outcome "instruments to improve the hygiene of the cleft area" was referred as what is considered to be conventional toothbrushes. Regarding that, only one study was found ${ }^{9}$ and stated that the use of a baby-sized toothbrush supplemented with an interspace brush is recommended in some situations to improve oral hygiene of the CLP children.
The data extracted from the other 40 studies include oral hygiene, not instruments, and were conveyed as bacterial plaque index and dental caries. These were considered as secondary outcomes and were organized in three tables, each addressing, respectively, the bacterial plaque assessed by any quantitative index (Table 1), the prevalence of dental caries assessed by $\mathrm{dmft} / \mathrm{dmfs}$ and/or DMFT/ DMFS (Table 2) and both issues (Table 3).

Plaque indexes in CLP patients (Table 1) were evaluated in eight studies conducted from 1999 to 2017, most of them cross-sectional (one case-control), and involving sample sizes from 15 to 400 individuals within the age range 3.5 to 49 years old. All studies showed that CLP patients presented high plaque indexes. ${ }^{3,10,17-20}$ These were worse in CLP patients than in controls ${ }^{3,18}$ and more serious in CLP type than in CP type. ${ }^{10,19,20}$

Sixteen studies were reported from 1999 to 2017 on the prevalence of dental caries in CLP individuals (Table 2), differing on the study type (systematic reviews and meta-analysis, narrative reviews, cross-sectional, retrospective, descriptive and case-control), geographic area, sample size and measured plaque indexes. All studies reported high prevalence of dental caries in the CLP population. Several studies showed that this prevalence was higher compared to common matched individuals, ${ }^{5,9,21}$ and two articles presented evidence of differences by cleft type (CL<CLP or CP) on the caries prevalence. ${ }^{14,22}$

Table 3 includes the articles that addressed oral hygiene based on these two subjects-plaque index and dental caries. Fourteen studies, including an epidemiological survey, and cross-sectional, 
case-control, prospective and observational studies, showed the same pattern compared to those that analysed these parameters separately. Oral hygiene (plaque index and prevalence of caries) is

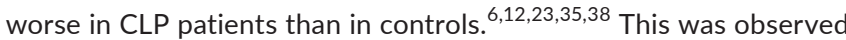
in patients in different phases of oral development, and it was similar in the primary, mixed and permanent dentitions, suggesting that the increased risk of oral problems persists. Just one article showed evidence of differences by gender, that is females had higher caries experience than males, and this was worse in patients with bilateral clefts. ${ }^{2}$ One study demonstrated differences by cleft type ( $C L<C L P$ or $\mathrm{CP}){ }^{26}$

Many studies also conducted a questionnaire addressing several variables related to oral hygiene. Data regarding the brushing habits were present in fourteen studies, $4,5,7,8,11,14-16,21-23$ and about half of them ${ }^{4,5,15,21,23,29}$ reported a frequency $\geq 2$ daily brushings that is higher in CLP patients than in controls. ${ }^{16,35}$ The use of fluoride products was reported in a variety of studies, ${ }^{4-6,8,12,16,21,29,34}$ and some of them showed that this was higher in CLP patients than in controls. ${ }^{6,12,21,34,35}$ When specified, toothpastes, ${ }^{5,35,36}$ mouthrinses, ${ }^{6,16,21,35}$ supplements, professional application or fluoridation programs ${ }^{4,12}$ were used. The type of feeding in young children is referred in one study ${ }^{24}$ and showed that those taking a bottle to bed presented an increased risk of developing tooth decay. In several studies, the questionnaire addressed the relevance of the education/ motivation of the parents and the importance of parental supervision for the oral health of their CLP children. ${ }^{11,12,16,24}$ Two studies showed that the mother supervision on toothbrushing is higher in CLP patients than that observed in the controls. ${ }^{12,16}$ One of these studies, dated from $1999^{24}$ and involving CLP children under 2 years of age $(n=123$ ), observed that parents of bottled fed and non-bottled fed children showed no difference in knowledge regarding oral health of their children. Meanwhile a study performed in 2006, ${ }^{16}$ involving 300 mothers and CLP children, 3-5 years old, observed that a percentage of mothers had some knowledge on the causes and prevention of dental caries in their children. Regarding parents' motivation, the old study, from $1999,{ }^{24}$ detected a lack of mothers' motivation to perform regular preventive dental home care for their children. Interestingly, a recent qualitative research (2017) from United Kingdom involving 22 parents and 16 CLP children aged 2-11 years old revealed that parents need support to maintain and prioritize regular toothbrushing within the demanding family life. ${ }^{11}$ Related to this, some studies stressed the relevance of care and prevention counselling to improve the oral health of CLP children. ${ }^{4,7,11,16,40}$ Others highlight the significance of including a dentist in the cleft team. ${ }^{7}$

\section{4 | DISCUSSION}

This systematic review selected and analysed the available information that deals with aspects related to oral hygiene in patients with CLP. At the beginning of the search, it was noted that most studies presented data mainly associated to aetiological, epidemiological and orthodontic aspects, and only few were specifically focused on oral hygiene and related issues, namely plaque indexes, prevalence of dental caries and oral hygiene routines. Thus, applying the inclusion criterion and the exclusion criteria, 39 studies were selected from a total of 270 potentially relevant articles published between 1997 and 2017.

Bone and dental development abnormalities hinder the removal of the bacterial plaque in children with CLP, which is a major predisposing factor for the development of dental caries. Thus, the selected research outcomes were related to bacterial plaque indexes, prevalence of dental caries and oral hygiene routines.

The relevance of oral hygiene in the bacterial plaque indexes and prevalence of dental caries is well known. In this review, the selected articles included information on the bacterial plaque indexes, ${ }^{3,10,17-20}$ the prevalence of dental caries ${ }^{1,5,9,14,16,21,22,24,29-32}$ and on both plaque indexes and dental caries. ${ }^{2,4,6,8,12,15,23,25,26,33-35,38}$ Data on bacterial plaque and/ or dental caries and oral hygiene were reported in almost half of the selected studies, but only eight studies addressed the three issues. $4,6,8,12,15,23,34,35$

Most studies reported a high prevalence of dental caries in children with $\operatorname{CLP}^{8,10,14,33,34}$ regardless the cleft type; however, few studies ${ }^{14,22,26}$ relate the type of cleft to the incidence of caries. Others ${ }^{2,26}$ report a direct link between the severity of the cleft and the experience of caries. This high risk of caries may be correlated with the anatomy of the region, as it may retain food in the cleft ${ }^{36,40}$ as well as malocclusion. ${ }^{10,20,36}$ Compared to the general population, the incidence of dental development abnormalities is greater in CLP patients, in which anomalies in the shape (dental fusion, geminations and conoids), ${ }^{8,35}$ the enamel structure (dental hypoplasia's) ${ }^{9,12,15,36}$ and the number (agenesis or supernumeraries) ${ }^{8}$ are among the most frequently observed. The predisposing factors to dental caries in CLP children are also associated to the cariogenic microbiota, ${ }^{3,12,14,16}$ the type, ${ }^{14,22,26}$ the gender, ${ }^{2}$ the breathing, ${ }^{35}$ the fear of brushing the cleft area, ${ }^{8}$ the mother's education ${ }^{14,22}$ and a greater concern with the corrective surgeries than with the prevention or the early treatment of caries lesion. ${ }^{2,8,35,36}$ Also, following the surgical procedures, the presence of the healing tissues poses additional difficulties to the local hygiene and favours the retention and/or hinders the control of bacterial plaque, resulting in high plaque indexes ${ }^{12,23}$ and increased risk of periodontal disease. ${ }^{19}$ This is especially relevant in the area adjacent to the cleft $\mathrm{ft}^{3,17,20}$ and in patients with oronasal communication. ${ }^{8,16}$

Oral hygiene routines (toothbrushing, use of fluoride products) were evaluated through a questionnaire, and although the relevance of this issue in the oral health of CLP children, these data were missing from many studies. ${ }^{1-3,9,10,17,19,20,25-28,30}$ Additionally, this did not improve over time. Even in the last decade, more than half of the studies focused on plaque indexes and/or dental caries (Tables 1-3). This is an important observation given the role of the oral hygiene in CLP children. Thus, much remains to be done to raise the awareness to the preventive dental care, both to health care workers and children/parents. In line with this, two studies conducted in USA to evaluate the feasibility of implementing Caries Management By Risk Assessment (CAMBRA) during the medical visit at an institutional tertiary care 
centre for children with craniofacial anomalies concluded that the basic oral hygiene standards were not met in this high-risk population. 5,29

Other pertinent observation is related to the education in oral hygiene and the motivation of the parents to perform regular preventive dental home care for their children. ${ }^{4,7,11,16}$ The few studies that included this information noted that parents have great limitations concerning the importance of oral hygiene $e^{4,11}$ and, additionally, they need support to maintain their intention to accomplish regular toothbrushing and to prioritize it within the context of demanding family life. ${ }^{11}$ Thus, continuous support and educational programmes on oral hygiene care, emphasizing its relevance to oral health and successful rehabilitation of CLP patients, are also essential for effective compliance. The importance of including a dentist in the cleft team is also emphasized. ${ }^{7}$

Perhaps the most unusual observation is that although the consensus on the poor oral hygiene of CLP children, no specific measures have been advanced to minimize this situation. For instance, toothbrushing and removal of dental plaque are strictly related, but poor attention has been given to the toothbrush. Only one of the studies ${ }^{9}$ mentions that a regular brush may not be effective in the hygiene of the cleft area. The authors propose that the use of a baby-sized toothbrush and an interspace brush might be valuable to clean hard to reach areas.

This review has strengths and limitations. The selection process was rigorous and extensive. The inclusion criterion was well definedinclusion of studies dealing with the oral hygiene in CLP children performed with a clinical purpose. Studies comprising data involving subjects with fixed appliances and bone grafts were excluded as these hamper clinical observation and brings an additional difficulty in maintaining the oral hygiene due to the fear of hurting the area undergoing surgery. Studies dealing with teeth anomalies and nutritional health were also excluded as they introduce confounding variables. Following the established selection criteria, the most relevant studies were included. However, the review did not consider articles that were not fully accessible or in another language other than English, which eventually might add some specific information on the subject. Another limitation was the great heterogeneity of the included studies regarding the geographic area, study population, study type, evaluation of the bacterial plaque and differences in the oral hygiene routines, which hinders the emerging of consensual patterns.

This review highlights some consensual information regarding the oral hygiene status of children with CLP. The commitment of paediatric dentistry professionals with the continuous dissemination of preventive measures and associated benefits is undoubtedly a challenge to be followed in order to improve the oral health status of these children. Preventive oral health programmes targeting this population and improving parent's knowledge on oral health are needed. It was also clear that there is a need of identifying a better solution to improve the hygiene of the cleft area. There are no studies dealing with specific strategies to minimize this problem, namely concerning the implementation of measures that effectively ensure a better oral hygiene. It is suggested that the development of a device/toothbrush with high efficacy in removing the dental plaque in the cleft area would minimize the complications associated with poor oral hygiene.

\section{5 | CONCLUSION}

The poor oral hygiene of CLP individuals is associated with high plaque indexes and prevalence of dental caries.

There is a clear need to improve the oral hygiene care of CLP children, but few studies were focused on specific preventive approaches. Development of devices especially designed to the hygiene of the cleft area and implementation of standardized prevention and control programs targeting education, motivation and compliance would contribute to improve oral health in CLP children.

\section{ACKNOWLEDGEMENTS}

M.C. Manso acknowledges Fundação para a Ciência e a Tecnologia through grant UID/Multi/04546/2016 and UID/ QUI/50006/2013-POCI/01/0145/FERDER/007265. Financial support from the European Union (FEDER funds POCl/01/0145/ FEDER/007265) and National Funds (FCT/MEC, Fundação para a Ciência e Tecnologia and Ministério da Educação e Ciência) under the Partnership Agreement PT2020 UID/QUI/50006/2013 is acknowledged.

M.H. Fernandes acknowledges the financial support from the European Union (FEDER funds POCI/01/0145/FEDER/007265) and National Funds (FCT/MEC, Fundação para a Ciência e Tecnologia and Ministério da Educação e Ciência) under the Partnership Agreement PT2020 UID/QUI/50006/2013.

All authors acknowledge the valuable critical revision and support from Prof. Dr. Tiago Coelho.

\section{DISCLOSURES}

None.

\section{ORCID}

Rita Rodrigues (iD https://orcid.org/0000-0002-7640-6993

Maria Helena Fernandes (iD https://orcid.org/0000-0001-9391-9574

Cátia Carvalho Silva (iD https://orcid.org/0000-0002-5274-1615

Ricardo Vardasca (iD https://orcid.org/0000-0003-4217-2882

Joaquim Mendes (D) https://orcid.org/0000-0003-4254-1879

Maria Conceição Manso (iD https://orcid.org/0000-0002-1774-1337

\section{REFERENCES}

1. Lages E, Marcos B, Pordeus IA. Oral health of individuals with cleft lip, cleft palate, or both. Cleft Palate Craniofac J. 2004;41(1):59-63.

2. Hazza'a AM, Rawashdeh MA, Al-Nimri K, Al Habashneh R. Dental and oral hygiene status in Jordanian children with cleft lip and palate: a comparison between unilateral and bilateral clefts. Int $J$ Dental Hygiene. 2011;9(1):30-36.

3. Perdikogianni H, Papaioannou W, Nakou M, Oulis C, Papagiannoulis L. Periodontal and microbiological parameters in children and adolescents with cleft lip and /or palate. Int J Pediatr Dent. 2009;19(6):455-467. 
4. Halițchi L, Zaharia A, Darabă O, et al. Epidemiological survey of tooth decay in young children with cleft lip and palate. Int J Med Dent. 2017;21(1), 37-41.

5. Howe BJ, Cooper ME, Wehby GL, et al. Dental decay phenotype in nonsyndromic orofacial clefting. J Dent Res. 2017;96(10):1106-1114.

6. Ahluwalia M, Brailsford SR, Tarelli E, et al. Dental caries, oral hygiene, and oral clearance in children with craniofacial disorders. J Dent Res. 2004;83(2):175-179.

7. Gopakumar M, Hegde AM. Parental attitude towards the provision of nonsurgical oral health care to children with oral clefts: an epidemiological survey. Int J Clin Pediatr Dent. 2010;3(1):35-37.

8. Sundell AL, Ullbro C, Marcusson A, Twetman S. Comparing caries risk profiles between 5 - and 10-year-old children with cleft lip and/ or palate and non-cleft controls. BMC Oral Health. 2015;15:85.

9. Rivkin CJ, Keith O, Crawford PJ, Hathorn IS. Dental care for the patient with a cleft lip and palate. Part 2: The mixed dentition stage through to adolescence and young adulthood. Br Dent J. 2000;188(3):131-134.

10. Boloor V, Thomas B. Comparison of periodontal status among patients with cleft lip, cleft palate, and cleft lip along with a cleft in palate and alveolus. J Indian Soc Periodontol. 2010;14(3):168-172.

11. Lin YL, Davies K, Callery P. Experience of maintaining tooth brushing for children born with a cleft lip and/or palate. BMC Oral Health. 2017;17(1):120.

12. Parapanisiou V, Gizani S, Makou M, Papagiannoulis L. Oral health status and behaviour of Greek patients with cleft lip and palate. Eur Arch Paediatr Dent. 2009;10(2):85-89.

13. Moher D, Liberati A, Tetzlaff J, Altman DG. Preferred reporting items for systematic reviews and meta-analyses: the prisma statement. PLoS Med. 2009;6(7):e1000097.

14. Bian Z, Du M, Bedi R, Holt R, Jin H, Fan M. Caries experience and oral health behavior in Chinese children with cleft lip and/or palate. Pediatr Dent. 2001;23(5):431-434.

15. Stec-Slonicz M, Szczepanska J, Hirschfelder U. Comparison of caries prevalence in two populations of cleft patients. Cleft Palate Craniofac J. 2007;44(5):532-537.

16. de Castilho AR, das Neves LT, de Carvalho Carrara CF. Evaluation of oral health knowledge and oral health status in mothers and their children with cleft lip and palate. Cleft Palate Craniofac J. 2006;43(6):726-730.

17. Wyrebek B, Cudzilo D, Plakwicz P. Evaluation of periodontal tissues in growing patients with bilateral cleft lip and palate. A pilot study. Dev Period Med. 2017;21(2):154-161.

18. Plakwicz P, Wyrebek B, Gorska R, Cudzilo D. Periodontal indices and status in 34 growing patients with unilateral cleft lip and palate: a splitmouth study. Int J Periodontics Restorative Dent. 2017;37(6):e344-e353.

19. Mutthineni RB, Nutalapati R, Kasagani SK. Comparison of oral hygiene and periodontal status in patients with clefts of palate and patients with unilateral cleft lip, palate and alveolus. J Indian Soc Periodontol. 2010;14(4):236-240.

20. Gaggl A, Schultes G, Karcher H, Mossbock R. Periodontal disease in patients with cleft palate and patients with unilateral and bilateral clefts of lip, palate, and alveolus. J Periodontol. 1999;70(2):171-178.

21. Mutarai T, RitthagolW, Hunsrisakhun J. Factors influencing early childhood caries of cleft lip and/or palate children aged 18 to 36 months in southern Thailand. Cleft Palate Craniofac J. 2008;45(5):468-472.

22. Ankola AV, Nagesh L, Hegde P, Karibasappa GN. Primary dentition status and treatment needs of children with cleft lip and/or palate. $J$ Indian Soc Pedod Prevent Dent. 2005;23(2):80-82.

23. Pisek A, Pitiphat W, Chowchuen B, Pradubwong S. Oral health status and oral impacts on quality of life in early adolescent cleft patients. J Med Assoc Thai. 2014;97(Suppl 10):S7-16.
24. Lin YT, Tsai CL. Caries prevalence and bottle-feeding practices in 2year-old children with cleft lip, cleft palate, or both in Taiwan. Cleft Palate Craniofac J. 1999;36(6):522-526.

25. Smallridge J, Hall AJ, Chorbachi R, et al. Functional outcomes in the cleft care UK study-part 3: oral health and audiology. Orthod Craniofac Res. 2015;18(Suppl 2):25-35.

26. Paul T, Brandt RS. Oral and dental health status of children with cleft lip and/or palate. Cleft Palate Craniofac J. 1998;35(4):329-332.

27. Stec M, Szczepanska J, Pypec J, Hirschfelder U. Periodontal status and oral hygiene in two populations of cleft patients. Cleft Palate Craniofac J. 2007;44(1):73-78.

28. de Almeida AL, Gonzalez MK, Greghi SL, Conti PC, Pegoraro LF. Are teeth close to the cleft more susceptible to periodontal disease? Cleft Palate Craniofac J. 2009;46(2):161-165.

29. Gaudilliere D, Thakur Y, Ku M, Kaur A, Shrestha P, Girod SC. Caries management by risk assessment in a cleft and craniofacial center. J Craniofac Surg. 2014;25(6):e529-536.

30. Foger D, Vélasco S, Esper LA, et al. Dental caries and oral healthrelated quality of life in cleft lip and palate patients: a pilot study. World J Dent. 2015;6(3):23-128.

31. Chapple J, Nunn J. The oral health of children with clefts of the lip, palate, or both. Cleft Palate Craniofac J. 2001;38(5):525-528.

32. Besseling $S$, Dubois $L$. The prevalence of caries in children with a cleft lip and/or palate in southern Vietnam. Cleft Palate Craniofac J. 2004;41(6):629-632.

33. Turner C, Zagirova AF, Frolova LE, Courts FJ, Williams WN. Oral health status of Russian children with unilateral cleft lip and palate. Cleft Palate Craniofac J. 1998;35(6):489-494.

34. Bokhout B, Hofman FX, van Limbeek J, Kramer GJ, Prahl-Andersen $B$. Incidence of dental caries in the primary dentition in children with a cleft lip and/or palate. Caries Res. 1997;31(1):8-12.

35. Freitas $A B$, de Barros LM, Fiorini JE, Boriollo MF, Moreira AN, Magalhaes CS. Caries experience in a sample of adolescents and young adults with cleft lip and palate in Brazil. Cleft Palate Craniofac J. 2013;50(2):187-191.

36. Shashni R, Goyal A, Gauba K, Utreja AK, Ray P, Jena AK. Comparison of risk indicators of dental caries in children with and without cleft lip and palate deformities. Contemporary Clinical Dentistry. 2015;6(1):58-62.

37. Tuaño-Cabrera CA, Ildefonso EC, Palabrica M. Caries experience in Filipino children with cleft lip and/or palate from the noordhoff craniofacial foundation, Philippines. Acta Medica Philippina. 2017;51(2):140.

38. Al-Wahadni A, Alhaija EA, Al-Omari MA. Oral disease status of a sample of Jordanian people ages 10 to 28 with cleft lip and palate. Cleft Palate Craniofac J. 2005;42(3):304-308.

39. Fadeyibi I, Sorunke M, Onigbinde O, Ogunbanjo V, Ogunbanjo B, Ademiluyi S. Oral health status of individuals with cleft lip, cleft palate or both in a Nigerian population. Maced J Med Sci. 2011;4(3):265-270.

40. Cheng LL, Moor SL, Ho CT. Predisposing factors to dental caries in children with cleft lip and palate: a review and strategies for early prevention. Cleft Palate Craniofac J. 2007;44(1):67-72.

How to cite this article: Rodrigues R, Fernandes $M H$, Bessa Monteiro A, et al. Are there any solutions for improving the cleft area hygiene in patients with cleft lip and palate? A systematic review. Int J Dent Hygiene. 2019;17:130-141. https://doi.org/10.1111/idh.12385 